\title{
Extramedullary hematopoiesis secondary to malignant solid tumors: a case report and literature review
}

This article was published in the following Dove Press journal:

Cancer Management and Research

\author{
Youting $\mathrm{Bao}^{1,2, *}$ \\ Zhichao Liu' ${ }^{2,3, *}$ \\ Meiying Guo ${ }^{2,4}$ \\ Butuo $\mathrm{Li}^{2,5}$ \\ Xindong Sun ${ }^{2}$ \\ Linlin Wang ${ }^{2}$
}

'Department of Oncology, Clinical College, Weifang Medical University, Weifang 261053, ${ }^{2}$ Department of Radiation Oncology, Shandong Cancer Hospital Affiliated to Shandong University, Shandong Academy of Medical Science, Jinan 250II7, ${ }^{3}$ Department of Oncology, School of Medicine and Life Sciences, University of Jinan-Shandong Academy of Medical Sciences, Jinan $250200,{ }^{4}$ Medical College of Shandong University, Jinan $250012,{ }^{5}$ Department of Oncology, Tianjin Medical University, Tianjin 300070, People's Republic of China

*These authors contributed equally to this work
Correspondence: Linlin Wang Department of Radiation Oncology, Shandong Cancer Hospital Affiliated to Shandong University, Shandong Academy of Medical Science, No 440, Ji Yan Road, Jinan, Shandong 250II7, People's Republic of China

Tel +8653I 67626142

Email wanglinlinatjn@163.com

\begin{abstract}
Extramedullary hematopoiesis (EMH) usually occurs in hematological disease, but more rarely develops in cases of malignant solid tumors. Due to its features on computed tomography (CT) and magnetic resonance imaging (MRI) that are atypical, EMH in tumor patients might easily be misdiagnosed as metastasis leading to the improper TNM staging and inappropriate therapy. Here, we reported the first case of pleural EMH occurring in a patient with esophageal carcinoma whose pleural lesion was first diagnosed as metastasis and confirmed EMH after the needle biopsy. In addition, a retrospective review was conducted by analyzing patients presented with EMH with malignant solid tumors from PubMed and Medline databases. A total of 42 solid tumor patients with EMH were enrolled, and breast cancer was the most common $(n=13,31.0 \%)$, followed by renal carcinoma $(n=7,16.7 \%)$ and lung cancer $(n=6,14.3 \%)$. A wide variety of body sites may be affected by EMH in malignant solid tumor patients, of which the lymph nodes $(n=8,19.0 \%)$ and liver $(n=7,16.7 \%)$ were the most common, followed by the kidney $(n=6,14.3 \%)$. All patients were diagnosed with EMH by excision, biopsy, or autopsy. Treatment strategies for EMH included surgery $(n=25,59.5 \%)$, hydroxyurea $(n=1,2.4 \%)$, and blood transfusions ( $\mathrm{n}=2,4.8 \%$ ); a further 14 patients (33.3\%) were subjected to clinical observation without intervention. Of the patients for whom outcome was reported, 10 patients maintained a good performance status $(23.8 \%)$ and a further six patients died from the malignant tumor. This was the first study to summarize the presentations of EMH in malignant solid tumors, and our findings might provide some useful guidance for clinical practice, especially for treating patients harboring nonresponse lesions during the antitumor treatment.
\end{abstract}

Keywords: extramedullary hematopoiesis, cancer, sarcoma, imaging features, biopsy

\section{Introduction}

Extramedullary hematopoiesis (EMH) is defined as the production of normal blood cells outside of the bone marrow. ${ }^{1,2}$ It is a compensatory mechanism that is closely related to inadequate functioning of medullary hematopoiesis, especially myeloproliferative disorders and hemolytic anemia. ${ }^{1,3}$ However, there have also been reports of EMH in cases of malignant solid tumors, including breast cancer, ${ }^{4}$ lung cancer, ${ }^{5}$ and Kaposi's sarcoma. ${ }^{6}$ The majority of patients are generally asymptomatic, but EMH may also manifest as a mass or organomegaly, which can be detected by imaging techniques. There is little information in the literature to guide the management of EMH in cases of malignant solid tumors due to the low incidence of this condition. Furthermore, in the absence of typical imaging characteristics of EMH within cases of malignant tumors, radiologists may misdiagnose $\mathrm{EMH}$ as malignancy, affecting clinical decision making. 
In the present study, we report a new case of pleural EMH occurring in a patient with esophageal cancer. In addition, we conduct a systematic review of case reports on EMH within malignant tumors in order to improve diagnosis, staging, and treatment of this disorder and better understand its prognosis.

\section{Case report}

A 48-year-old Asian man sought medical assessment on October 25, 2016 due to a 1-month history of black stool and progressive difficulty in swallowing. He had no medical history of hematological system disease. Contrast-enhanced computed tomography (CT) scans of the chest revealed a significantly thickened esophageal wall, which was considered to be an esophageal neoplasm (red arrows in Figure 1D); the pleural soft tissue at the eighth right posterior rib was perceived to be metastasis (yellow arrows in Figure 1A and
D). Pathological analysis of a gastroscopic biopsy revealed squamous cell carcinoma (Figure 2A). Physical examination indicated no significant abnormalities. Laboratory studies included a red blood cell count of $3.56 \times 10^{12} / \mathrm{L}$ and a hemoglobin density of $105 \mathrm{~g} / \mathrm{L}$. The fecal occult blood test was positive. Moreover, biochemical tests and tumor markers in the patient's serum were negative.

The patient was diagnosed with esophageal squamous cell carcinoma (ESCC) with pleural metastasis based on radiographic examination combined with the biopsy pathology, and the clinical stage was classified as IV (T4bN0M1) according to the 7th edition of the American Joint Committee on Cancer staging guidelines. The patient subsequently underwent a total of four cycles of triweekly chemotherapy, consisting of docetaxel $\left(70 \mathrm{mg} / \mathrm{m}^{2}\right.$ body surface area on days 1 and 8$)$ combined with cisplatin $\left(70 \mathrm{mg} / \mathrm{m}^{2}\right.$ body surface
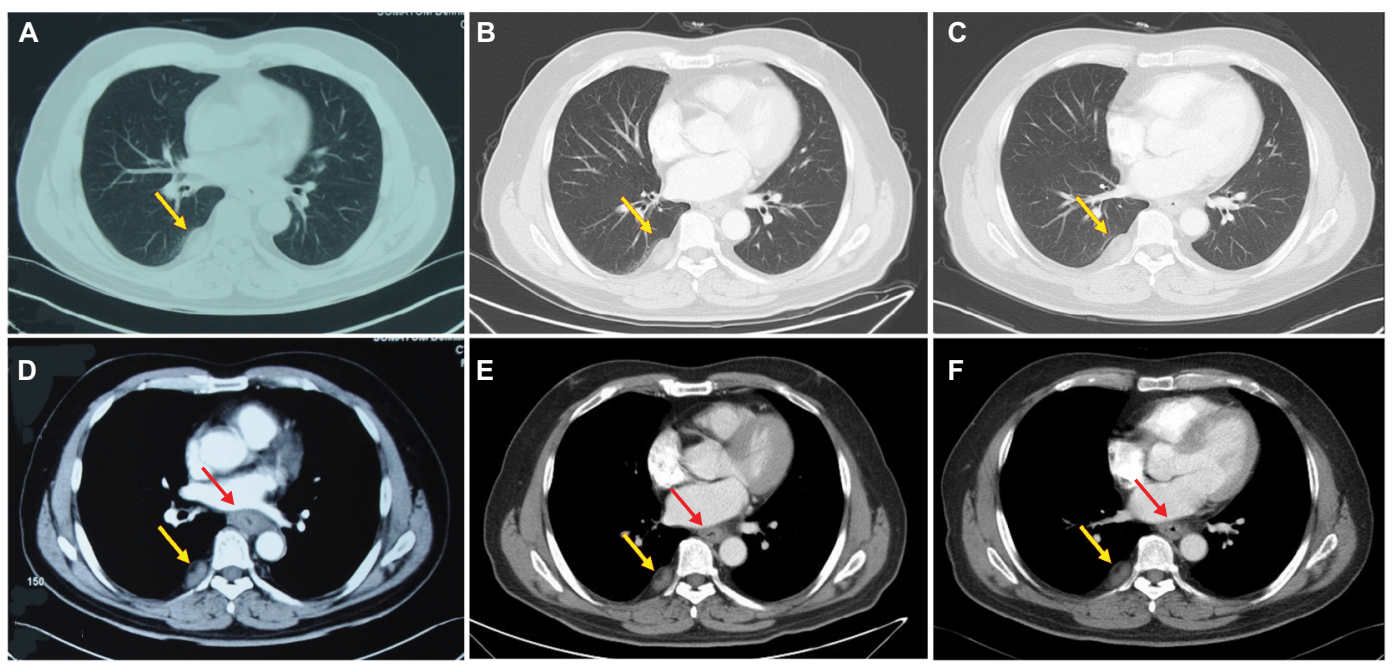

Figure I Changes in CT in the ESCC.

Notes: (A and $\mathbf{D})$ the well-circumscribed mass in right pleura (yellow arrows) and thickened esophageal wall (red arrow) prior to treatment, respectively. (B and $\mathbf{E}$ ) Reduction in the lesions for the esophageal wall (red arrow) and stabilization of the lesion for the right pleura (yellow arrows) after two cycles of TP chemotherapy. (C and F) Esophageal wall (red arrow) thickness decrease and pleural lesion (yellow arrows) size stability after four cycles of TP chemotherapy.

Abbreviations: CT, computed tomography; ESCC, esophageal squamous cell carcinoma; TP, cisplatin-docetaxel.
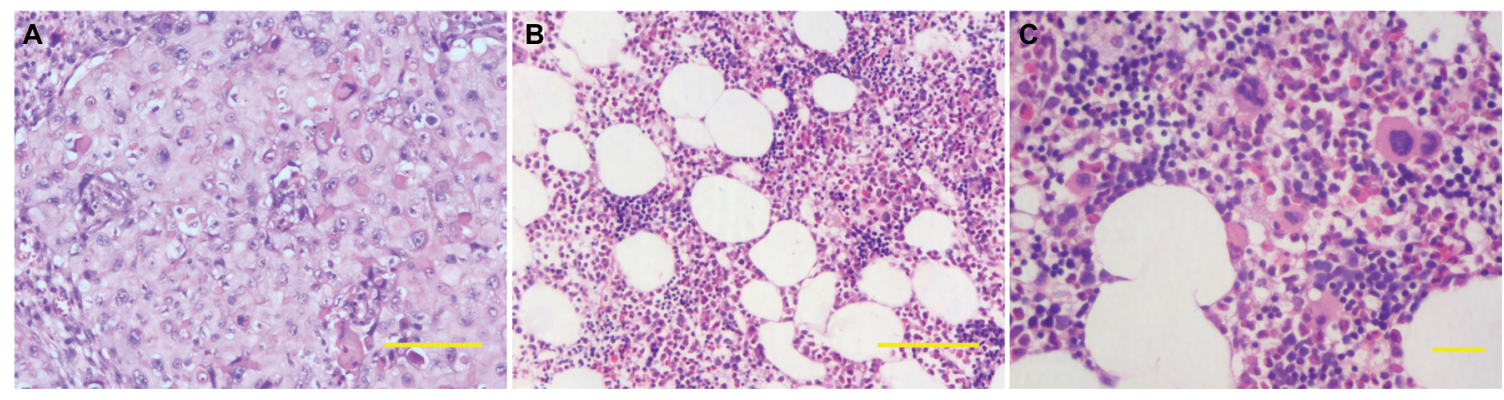

Figure 2 (A) Pathocytology of esophageal tissue revealed squamous cell carcinoma. (B and C) Pathocytology of pleural soft tissue showed a few of lymphocytes, erythropoiesis, megakaryocytes, and degraded cells.

Notes: $(\mathbf{A}$ and B) H\&E staining $\times 100$. Scale bar: $100 \mu \mathrm{m}$ and $(\mathbf{C}) \mathrm{H} \& E$ staining $\times 200$. Scale bar: $100 \mu \mathrm{m}$.

Abbreviation: H\&E, hematoxylin and eosin. 


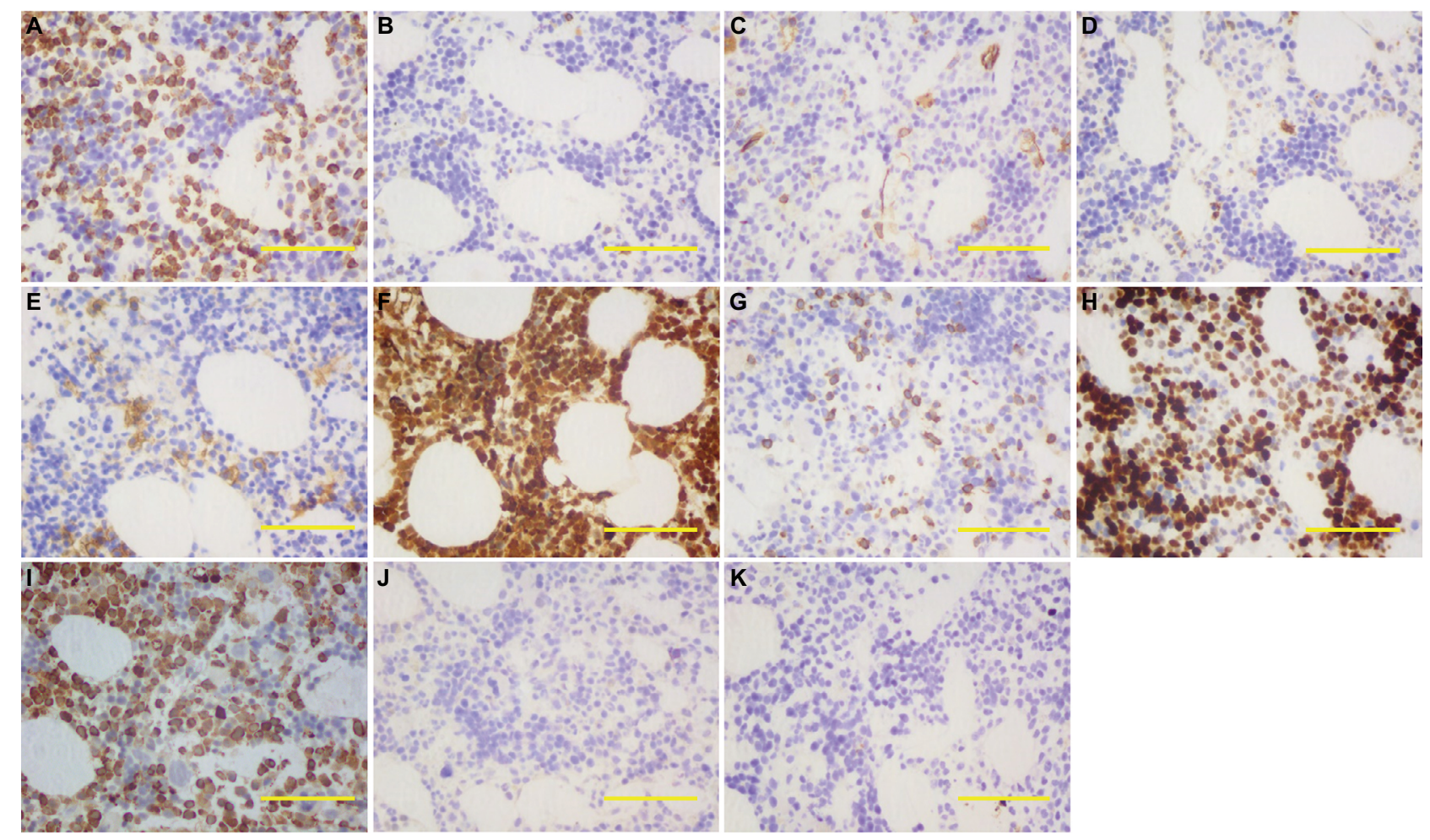

Figure 3 Immunohistochemical of pleural mass revealed EMH.

Notes: Immunohistochemical staining $\times 200$. Scale bar: $200 \mu \mathrm{m}$. (A) CDI5+; (B) CD20+; (C) CD34+; (D) CD30+; (E) CD38+; (F) CD68+; (G) $\mathrm{CD7}^{+}$; (H) Ki67 $(80-90 \%$; (I) lysozyme'; (J) CK5-; and (K) CK7-.

Abbreviation: $\mathrm{EMH}$, extramedullary hematopoiesis.

area on days 1-3). According to response evaluation criteria in solid tumors criteria, the patient achieved partial remission and stable disease (SD) of the original esophageal mass after two and four cycles of chemotherapy, respectively (Figure 1B, C, E, and F). However, the right pleural nodule was not observed to change after two therapeutic assessments.

A CT-guided percutaneous needle biopsy of the pleura was performed. Pathological analysis revealed a few lymphocytes, erythropoiesis, megakaryocytes, and degraded cells (Figure 2B and C). Immunohistochemical findings revealed positive staining for CD68, lysozyme, CD15, CD7, CD20, CD30, CD38, and CD34, while CK7 and CK5 staining was absent, and the Ki-67 index was $80-90 \%$, supporting a diagnosis of EMH (Figure 3). As the diagnosis of pleural metastasis from esophageal cancer was excluded, the TNM classification of the esophageal tumor was updated to T4bN0M0, stage IIIC. In combination with enhanced $\mathrm{CT}$, intensity-modulated radiation therapy was administered only to the esophageal lesion with the use of X-ray generated at $6 \mathrm{MV}$. The post-treatment $\mathrm{CT}$ and magnetic resonance imaging (MRI) scans, performed 1 month after the completion of the treatments, revealed a decrease in the thickness of the esophageal wall, which was considered to represent a partial response. During the whole course of chemotherapy and radiotherapy, the pleural EMH did not alter in size and the patient had no chest pain or shortness of breath (Figures 4A and B and 5).

This case report was approved by the Institutional Review Board of Shandong Cancer Hospital Affiliated to Shandong University, and the patient has provided written informed consent for permitting the case details and accompanying pictures to be published publicly.

\section{Methods}

A retrospective chart review was conducted on all identified case reports. We comprehensively searched the PubMed and Medline databases for articles published between 1980 and 2017, using the search terms "extramedullary haematopoiesis", "cancer", and "sarcoma". Searches were limited to studies on human subjects. All case reports were included according to the eligibility criteria and are presented in Table 1. A manual search of references was implemented in 


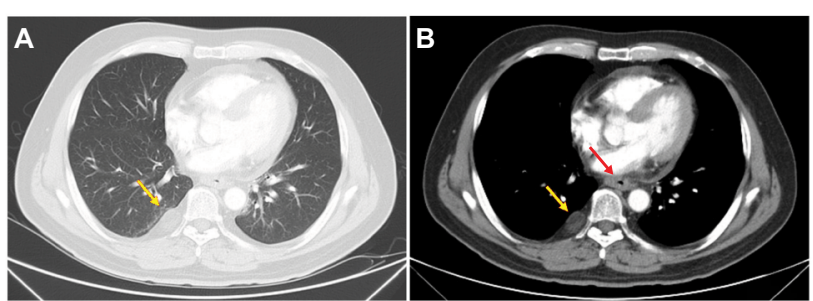

Figure 4 Variations in CT in the ESCC I month after finishing all the treatments. Note: (A and B) The stabilization of the right pleural mass (yellow arrows) and decrease of the thickened esophageal wall (red arrow) after the treatment, respectively.

Abbreviations: CT, computed tomography; ESCC, esophageal squamous cell carcinoma.

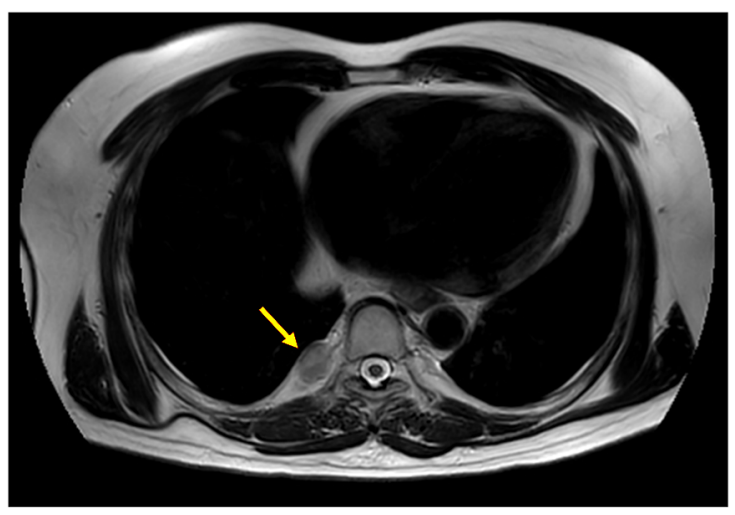

Figure 5 T2W/TSE sagittal MRI image I month after the completion of all the treatments, showing no considerable change in the size of the right pleural lesion (yellow arrow).

Abbreviations: MRI, magnetic resonance imaging; T2W/TSE, T2 weighted / turbo spin echo.

Table I Eligibility criteria for the literature review

\section{Condition}

- Articles published from 1980 to 2017

- Published in the English language

- Confirmed diagnosis of EMH through pathological examination

- All patients were diagnosed with malignant solid tumors

- Confirmed the location of EMH by imaging and surgery

Abbreviation: $\mathrm{EMH}$, extramedullary hematopoiesis.

relevant articles. The following data were collected from each case report: patient age and gender, type of malignant solid tumor, location of EMH, presence of hematopathy, type of therapy, and reported outcome (Table S1).

Pure malignant solid tumors were defined as those with no reported hematopathy. Malignant solid tumors complicated by hematopathy included cases of thalassemia, hemolytic anemia, sickle cell anemia, thrombotic thrombocytopenic purpura, and primary myelofibrosis. Pernicious anemia was defined as anemia occurring in malignant tumor patients secondary to nonhematological disease. Diagnosis patterns included excision (defined as surgical removal of the entirety of the mass), biopsy, and autopsy. Treatment strategies included observation (defined as no reported intervention), surgery (defined as complete excision), hydroxyurea, and blood transfusion. If imaging studies reported no change on follow-up or no explicit statement of symptomatology, the outcome was assumed to be SD.

\section{Results}

A total of 35 unique articles comprising 42 cases of EMH occurring with a malignant solid tumor were identified in the literature, ${ }^{1,4-37}$ as shown in Table S1. These patients included 13 males and 28 females, ranging in age from 1 to 84 years (mean, 52.4 years). The most common malignancies were breast cancer $(n=13,31.0 \%)$, renal cancer $(n=7,16.7 \%)$, and lung cancer $(n=6,14.3 \%)$ (Table 2$)$. EMH could develop in a variety of tissues and organs, including the lymph nodes $(n=8$, $19.0 \%)$, liver $(n=7,16.7 \%)$, and kidney $(n=6,14.3 \%)$ (Table 3$)$.

Table 2 Summary of the malignant solid tumors

\begin{tabular}{ll}
\hline Malignant solid tumor & Total patients, n (\%) \\
\hline Breast cancer & $\mathrm{I} 3(3 \mathrm{I} .0)$ \\
Renal cancer & $7(\mathrm{I} 6.7)$ \\
Lung cancer & $6(\mathrm{I} 4.3)$ \\
Colon carcinoma & $3(7.1)$ \\
Liver cancer & $2(4.8)$ \\
Endometrial adenosarcoma & $2(4.8)$ \\
Prostate cancer & $\mathrm{I}(2.4)$ \\
Adrenal carcinoma & $\mathrm{I}(2.4)$ \\
Endometrial carcinoma & $\mathrm{I}(2.4)$ \\
Cutaneous basal cell carcinomas & $\mathrm{I}(2.4)$ \\
Bladder carcinoma & $\mathrm{I}(2.4)$ \\
Kaposi sarcoma & $\mathrm{I}(2.4)$ \\
Ovarian endometrioid adenocarcinoma & $\mathrm{I}(2.4)$ \\
Ovarian leiomyosarcoma & $\mathrm{I}(2.4)$ \\
Melanoma & $\mathrm{I}(2.4)$ \\
\hline
\end{tabular}

Table 3 Summary of the extramedullary hematopoiesis sites

\begin{tabular}{ll}
\hline Sites & Total patients, $\mathbf{n}(\%)$ \\
\hline Lymph nodes & $8(19.0)$ \\
Liver & $7(16.7)$ \\
Kidney & $6(14.3)$ \\
Paraspinal region & $4(9.5)$ \\
Peritoneum & $4(9.5)$ \\
Spleen & $3(7.1)$ \\
Pleura & $2(4.8)$ \\
Breast & $2(4.8)$ \\
Presacral region & $2(4.8)$ \\
Bronchia & $\mathrm{I}(2.4)$ \\
Adrenal gland & $\mathrm{I}(2.4)$ \\
Endometrium & $\mathrm{I}(2.4)$ \\
Mesenterium & $\mathrm{I}(2.4)$ \\
Pancreas & $\mathrm{I}(2.4)$ \\
Ureter & $\mathrm{I}(2.4)$ \\
\hline
\end{tabular}


The majority of patients were asymptomatic, but physical and imaging findings of 13 patients $(31.0 \%)$ revealed hepatomegaly or splenomegaly (Table 4). In 12 of the 42 patients, malignant solid tumors were reported to be combined with hematopathy, including thalassemia $(\mathrm{n}=1)$, hemolytic anemia $(n=2)$, sickle cell anemia $(n=1)$, primary myelofibrosis $(n=6)$, thrombotic thrombocytopenic purpura

Table 4 Summary of data collected from case reports included in the literature review

\begin{tabular}{|c|c|}
\hline Variable & $\mathbf{n}$ \\
\hline \multicolumn{2}{|l|}{ Age, years } \\
\hline Mean & 52.4 \\
\hline Range & $\mathrm{I}-84$ \\
\hline \multicolumn{2}{|l|}{ Gender } \\
\hline Male & 13 \\
\hline Female & 28 \\
\hline \multicolumn{2}{|l|}{ Etiology } \\
\hline Pure malignant solid tumor & 31 \\
\hline \multicolumn{2}{|l|}{ Malignant solid tumor with hematopathy } \\
\hline Thalassemia & $\mathrm{I}$ \\
\hline Hemolytic anemia & 2 \\
\hline Sickle cell anemia & I \\
\hline Myelofibrosis & 6 \\
\hline Thrombotic thrombocytopenic purpura & I \\
\hline Others & $\mathrm{I}$ \\
\hline \multicolumn{2}{|l|}{ Physical examination } \\
\hline Hepatomegaly & 3 \\
\hline Splenomegaly & 6 \\
\hline Hepatomegaly and splenomegaly & 4 \\
\hline \multicolumn{2}{|l|}{ Imaging examination } \\
\hline X-ray photography & 9 \\
\hline Ultrasound & 11 \\
\hline Computed tomography & 20 \\
\hline MRI & 5 \\
\hline${ }^{18} \mathrm{~F}-\mathrm{FDG}$ PET & 3 \\
\hline \multicolumn{2}{|l|}{ Acquisition of pathologic tissue } \\
\hline Excision & 25 \\
\hline Biopsy & 14 \\
\hline Autopsy & 3 \\
\hline \multicolumn{2}{|l|}{ Histopathologic component } \\
\hline Pure EMH & 29 \\
\hline Mixed EMH & 13 \\
\hline \multicolumn{2}{|l|}{ Bone marrow biopsy } \\
\hline Associated with hematopathy & 6 \\
\hline Normal bone marrow & 4 \\
\hline \multicolumn{2}{|l|}{ Therapy method } \\
\hline Surgery & 25 \\
\hline Hydroxyurea & 1 \\
\hline Blood transfusions & 2 \\
\hline Observation & 14 \\
\hline \multicolumn{2}{|l|}{ Outcome } \\
\hline Stable disease & 10 \\
\hline Died of malignancy & 6 \\
\hline
\end{tabular}

Note: Mixed EMH is that the EMH was present in the tumor tissues.

Abbreviations: EMH, extramedullary hematopoiesis; ${ }^{18} \mathrm{~F}-\mathrm{FDG}$ PET, ${ }^{18} \mathrm{~F}$-fluoro-2 deoxy-d-glucose positron emission tomography; MRI, magnetic resonance imaging. $(\mathrm{n}=1)$, and unknown disease $(\mathrm{n}=1)$. A further three patients suffered from pernicious anemia. Of the 12 patients with hematopathy, four patients exhibited malignant solid tumors secondary to hematological disease, six patients developed hematological disease secondary to a malignant solid tumor, and two patients were diagnosed with hematological disease and malignant solid tumor simultaneously. However, the mutual mechanisms of EMH, tumor, and hematological disease remain unclear.

The majority of the patients $(\mathrm{n}=27,64.3 \%)$ underwent imaging examinations, including X-ray imaging $(\mathrm{n}=9$, $21.4 \%)$, ultrasound $(n=11,26.2 \%), C T(n=20,47.6 \%)$, MRI $(\mathrm{n}=5,11.9 \%)$, and ${ }^{18} \mathrm{~F}$-fluoro-2-deoxy-D-glucose positron emission tomography $\left({ }^{18} \mathrm{~F}-\mathrm{FDG}\right.$ PET) $(\mathrm{n}=3,7.1 \%)$ (Table 4). All cases were diagnosed as EMH by pathological examination, including 25 patients through surgery (59.5\%), 14 patients through biopsy (33.3\%), and three patients through autopsy (7.1\%). On pathological examination, tissue composition included pure EMH $(\mathrm{n}=29,69.0 \%)$ and mixed EMH $(\mathrm{n}=13,31.0 \%)$, in which EMH was present in the tumor tissues. A total of 10 patients (23.8\%) were recorded to receive bone marrow biopsy assay, six of whom were in accordance with the diagnosis of hematological diseases and the remaining patients showed normal marrow (Table 4).

Antitumor treatments were administered to $69.4 \%$ of patients, and EMH was treated with surgical excision $(\mathrm{n}=25$, $59.5 \%)$, hydroxyurea $(\mathrm{n}=1,2.4 \%)$, blood transfusion $(\mathrm{n}=2$, $4.8 \%$ ), or clinical observation ( $\mathrm{n}=14,33.3 \%)$. Notably, 25 patients underwent surgery in an attempt to remove the cancer and the subsequent postoperative pathological examination revealed the presence of EMH. Of the patients for whom outcome was reported, 10 patients maintained a good performance status (23.8\%) and a further six patients died from the malignant tumor (Table 4).

\section{Discussion}

EMH refers to the presence of hematopoietic elements outside the bone marrow, causing reduced erythrocyte production or accelerated destruction. ${ }^{1}$ Although this process may be physiological during the fetal stage, its occurrence after birth is usually considered abnormal. ${ }^{20,38} \mathrm{EMH}$ is typically associated with hematological disease, such as myelofibrosis and hemolytic anemia. ${ }^{1,3}$ Reports of EMH in cases of malignant solid tumor are less common.

Most patients are asymptomatic; however, any symptoms exhibited correspond to the location of EMH. For example, lung EMH may cause a pneumonia-like process and patients may present with a cough and sputum production; ${ }^{38}$ serosal 
EMH may lead to pleural effusion and ascites, with patients presenting with chest congestion, labored breathing, and abdominal distension or pain; ${ }^{38}$ and paravertebral EMH occupying the epidural space of the spinal canal may lead to the compression of nerve roots, with patients complaining of lumbago. ${ }^{39}$ In the present study, we identified two cases of pleural effusion and one patient with osphyalgia due to nerve root compression. However, the statistics indicated that symptoms are likely to be atypical in the malignant solid tumors.

The etiology of EMH in patients with solid tumors remains unclear. Granulocyte colony-stimulating factor (GCSF) may be an inducing factor of EMH.,9,14,17,21,40 In the present review, it was identified that five patients had been administered G-CSF during chemotherapy and radiotherapy due to chemotherapy-related bone marrow suppression. As a growth factor, G-CSF can stimulate the bone marrow to produce granulocytes, thereby increasing the release of granulocytes into the blood, by promoting stem cell production in the bone marrow. ${ }^{21}$ Additionally, it has been reported that doxorubicin, which is widely used as a neoadjuvant chemotherapy for breast cancer, is potentially involved in the etiopathogenesis of EMH in animal models without the administration of G-CSF.4, ${ }^{41}$ Thus, chemotherapeutic agents may also play roles in the pathogenesis of EMH. Furthermore, some abnormal cytokine or paracrine growth factors may be secreted by tumors, which may evoke the differentiation of stem cells into hematopoietic cells and stimulate regional hyperplasia of circulating hematopoietic progenitors. ${ }^{3}$ Moreover, three cases of pernicious anemia were identified in the present study; the shortage of erythrocytes in these patients could evoke a natural homeostatic response to increase the production of red blood cells by a compensatory mechanism of the bone marrow. ${ }^{3}$ Thus, the pathogenesis of EMH in cases of malignant solid tumors is very complicated and requires further study.

Among the reviewed cases, the majority of patients $(n=27,64.3 \%)$ received imaging examinations. X-ray and ultrasound imaging revealed abnormal masses. CT imaging was performed for 20 patients (47.6\%); on this imaging modality, EMH appeared as a well-circumscribed, inhomogeneous, hypovascular mass, often interspersed with areas of fat attenuation and without calcification or bone destruction. EMH can also appear with heterogeneous enhancement on contrast-enhanced CT. ${ }^{5,7,13,15,16,19,27,42-45}$ Among the five patients who underwent MRI (11.9\%), EMH appeared with a higher signal intensity than that of the adjacent normal tissue on T1- and T2-weighted images, with intermediate to high signal intensity particularly noted on T2-weighted images. ${ }^{42-45}$ EMH also contained lipid components, in which the enhancement was variable. ${ }^{23,24,42-45}$ The aforementioned imaging features of EMH were atypical and similar to those of tumors, and therefore, EMH can be easily misdiagnosed. Aspiration cytology or biopsy is amenable for the accurate diagnosis of EMH, which had hematopoietic elements, including erythroid, myeloid precursors, and megakaryocytes. ${ }^{35,36,38}$ In this study, 14 of the 27 patients who underwent imaging examination were not initially diagnosed with EMH. This is exemplified by our reported case of esophageal cancer, where the contrast-enhanced CT findings of pleural soft tissue were originally misdiagnosed as pleural metastases. Subsequently, a CT-guided pleural aspiration biopsy led to the correct diagnosis of EMH.

It is usually unnecessary to treat asymptomatic patients with EMH, whereas there are several options for the treatment of symptomatic patients, including hydroxyurea, transfusion, radiotherapy, and surgery. ${ }^{43}$ In the reviewed cases, 25 $(59.5 \%)$ patients underwent surgery in an attempt to remove the cancer, and resultant postoperative pathological examination revealed the presence of EMH. All three patients who received hydroxyurea and blood transfusions eventually died from the malignant solid tumor. Figure 6 illustrates the diagnosis and treatment of EMH in cases of malignant solid tumor in a simplified sequence flow diagram.

Research indicates that antitumor therapy is crucial in cases of malignant tumor with EMH in order to prevent the development of the cancer and improve the survival of patients. Radiotherapy may result in the remission of symptoms and reduction in the volume of the EMH mass, representing an effective treatment strategy, since the hematopoietic tissue is extremely radiosensitive. ${ }^{1,38}$ Numerous studies have indicated that EMH does not affect the prognosis of patients, and the follow-up outcomes of EMH are fairly satisfactory in the context of hematological diseases. ${ }^{38} \mathrm{EMH}$ did not seem to affect the outcomes of malignant solid tumor cases according to our retrospective analysis, since all six of the mortalities were due to the malignant solid tumor rather than EMH.

There were several limitations inherent to our study. First, as it is a review of case reports, complete information regarding demographics and follow-up data are lacking. The imaging examinations, diagnostic approaches, and subsequent treatments were often based on the emphasis point of the journal in which the report was published. Finally, the retrospective manner of data collection may have introduced bias. Despite these limitations, this is, to the best of our knowledge, the first study to summarize the presentations of 


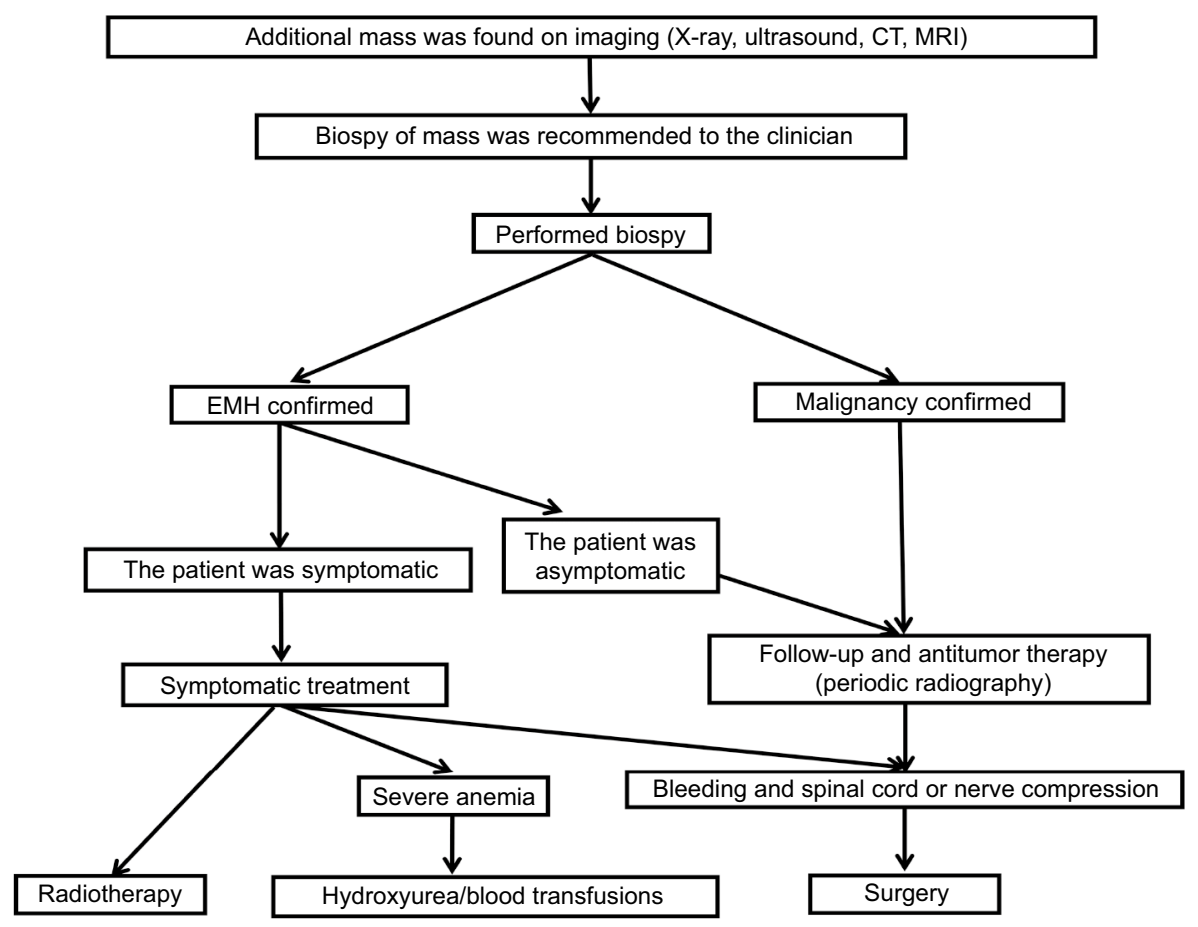

Figure 6 Process for the diagnosis and treatment of EMH in malignant solid tumors.

Abbreviations: $\mathrm{CT}$, computed tomography; $\mathrm{EMH}$, extramedullary hematopoiesis; MRI, magnetic resonance imaging.

EMH in malignant solid tumors and provide some guidance for clinical practice.

\section{Conclusion}

We present a novel case of a patient with esophageal cancer and pleural EMH. Based on the literature review on EMH in malignant solid tumors, various mechanisms for the formation of EMH have been proposed, including induction by G-CSF, stimulation by chemotherapeutic agents, secretion of cytokines, and pernicious anemia. EMH is a benign lesion but can be challenging to diagnose on the basis of imaging findings alone. Biopsy was the most common method for accurately diagnosing the benign and malignant masses. Antitumor therapy should be the main focus for asymptomatic patients. For patients with symptomatic EMH, treatments such as radiotherapy and excision may be considered if symptoms are unremitting.

\section{Acknowledgments}

We are grateful to Spandidos Language Editing Service for their contribution in polishing language and thank the patient and his family members who agreed to publish this case.

\section{Disclosure}

The authors report no conflicts of interest in this work.

\section{References}

1. Vassiliou V, Papamichael D, Lutz S, et al. Presacral extramedullary hematopoiesis in a patient with rectal adenocarcinoma: report of a case and literature review. J Gastrointest Cancer. 2012;43(suppl 1): S131-S135.

2. Munn RK, Kramer CA, Arnold SM. Spinal cord compression due to extramedullary hematopoiesis in beta-thalassemia intermedia. Int $J$ Radiat Oncol Biol Phys. 1998;42(3):607-609.

3. O'Malley DP. Benign extramedullary myeloid proliferations. Mod Pathol. 2007;20(4):405-415.

4. Wang J, Darvishian F. Extramedullary hematopoiesis in breast after neoadjuvant chemotherapy for breast carcinoma. Ann Clin Lab Sci. 2006;36(4):475-478.

5. Hsu FI, Filippa DA, Castro-Malaspina H, Downey RJ. Extramedullary hematopoiesis mimicking metastatic lung carcinoma. Ann Thorac Surg. 1998;66(4):1411-1413.

6. Pantanowitz L, Kuperman M, Goulart RA. Clinical history of HIV infection may be misleading in cytopathology. Cytojournal. 2010;7:7.

7. Meykler S, Obstfeld A, Jhala N, Vergara N, Gupta PK. Pleural mass forming extramedullary hematopoiesis masquerading as a malignant neoplasm. Diagn Cytopathol. 2015;43(12):996-999.

8. Bowen JM, Perry AM, Quist E, Akhtari M. Extramedullary hematopoiesis in a sentinel lymph node as an early sign of chronic myelomonocytic leukemia. Case Rep Pathol. 2015;2015:594970.

9. Takhar AS, Ney A, Patel M, Sharma A. Extramedullary haematopoiesis in axillary lymph nodes following neoadjuvant chemotherapy for locally advanced breast cancer. BMJ Case Rep. 2013;2013:8943.

10. Ardakani NM, Kumarasinghe MP, Spagnolo DV, Stewart CJ. Extramedullary hematopoiesis associated with organizing peritoneal hemorrhage: a report of 5 cases in patients presenting with primary gynecologic disorders. Int J Gynecol Pathol. 2014;33(3):317-322.

11. Tokumitsu S, Tokumitsu K, Kohnoe K, Takeya M, Takeuchi T. Extramedullary hematopoiesis presenting as mediastinal tumor. Acta Pathol Jpn. 1980;30(2):315-322. 
12. Yablonski-Peretz T, Sulkes A, Polliack A, Weshler Z, Okon E, Catane R. Secondary myelofibrosis with metastatic breast cancer simulating agnogenic myeloid metaplasia: report of a case and review of the literature. Med Pediatr Oncol. 1985;13(2):92-96.

13. Lemos LB, Baliga M, Benghuzzi HA, Cason Z. Nodular hematopoiesis of the liver diagnosed by fine-needle aspiration cytology. Diagn Cytopathol. 1997;16(1):51-54.

14. Prieto-Granada C, Setia N, Otis CN. Lymph node extramedullary hematopoiesis in breast cancer patients receiving neoadjuvant therapy: a potential diagnostic pitfall. Int J Surg Pathol. 2013;21(3):264-266.

15. Crider S, Kroszer-Hamati A, Krishnan K. Isolated pancreatic extramedullary hematopoiesis. Acta Haematol. 1998;99(1):38-40.

16. Tamiolakis D, Venizelos J, Prassopoulos P, et al. Intrahepatic extramedullary hematopoietic tumor mimicking metastatic carcinoma from a colonic primary. Onkologie. 2004;27(1):65-67.

17. Du E, Overstreet K, Zhou W, et al. Fine needle aspiration of splenic extramedullary hematopoiesis presenting as a solitary mass. A case report. Acta Cytol. 2002;46(6):1138-1142.

18. Millar EK, Inder S, Lynch J. Extramedullary haematopoiesis in axillary lymph nodes following neoadjuvant chemotherapy for locally advanced breast cancer - a potential diagnostic pitfall. Histopathology. 2009;54(5):622-623.

19. Yang X, Bhuiya T, Esposito M. Sclerosing extramedullary hematopoietic tumor. Ann Diagn Pathol. 2002;6(3):183-187.

20. Talmon GA. Pure erythropoiesis in clear cell renal cell carcinoma. Int J Surg Pathol. 2010;18(6):544-546.

21. Celik B, Bulut T, Sedele M, Sezer C, Karakus V. Extramedullary hematopoiesis within cystic renal cell carcinoma with oncocytic and chromophobe cell types: a case report. Oncol Lett. 2014;7(3):909-913.

22. Orphanidou-Vlachou E, Tziakouri-Shiakalli C, Georgiades CS. Extramedullary hemopoiesis. Semin Ultrasound CT MR. 2014;35(3):255-262.

23. Tamm EP, Rabushka LS, Fishman EK, Hruban RH, Diehl AM, Klein A. Intrahepatic, extramedullary hematopoiesis mimicking hemangioma on technetium-99m red blood cell SPECT examination. Clin Imaging. 1995;19(2):88-91.

24. Arkadopoulos N, Kyriazi M, Yiallourou AI, et al. A rare coexistence of adrenal cavernous hemangioma with extramedullar hemopoietic tissue: a case report and brief review of the literature. World J Surg Oncol. 2009; $7: 13$

25. Groisman GM. Lobular carcinoma of the breast metastatic to the spleen and accessory spleen: report of a case. Case Rep Pathol. 2016;2016:5160180.

26. Dekmezian R, Sneige N, Popok S, Ordonez NG. Fine-needle aspiration cytology of pediatric patients with primary hepatic tumors: a comparative study of two hepatoblastomas and a liver-cell carcinoma. Diagn Cytopathol. 1988;4(2):162-168.

27. Paydas S, Sargin O, Gonlusen G. PET CT imaging in extramedullary hematopoiesis and lung cancer surprise in a case with thalassemia intermedia. Turk J Haematol. 2011;28(1):60-62.

28. Chou S, Subramanian V, Lau HM, Achan A. Renal anastomosing hemangiomas with a diverse morphologic spectrum: report of two cases and review of literature. Int J Surg Pathol. 2014;22(4):369-373.
29. Lewis DJ, Moul JW, Williams SC, Sesterhenn IA, Colon E. Perirenal liposarcoma containing extramedullary hematopoiesis associated with renal cell carcinoma. Urology. 1994;43(1):106-109.

30. Varras M, Stylianido A, Akrivis C, Galanis P, Stefanaki S, Antoniou N. Extramedullary hematopoiesis in the uterine isthmus: a case report and review of the literature. Eur J Gynaecol Oncol. 2002;23(3): 227-230.

31. Lara JF, Rosen PP. Extramedullary hematopoiesis in a bronchial carcinoid tumor. An unusual complication of agnogenic myeloid metaplasia. Arch Pathol Lab Med. 1990;114(12):1283-1285.

32. Policarpio-Nicolas ML, Bregman SG, Ihsan M, Atkins KA. Massforming extramedullary hematopoiesis diagnosed by fine-needle aspiration cytology. Diagn Cytopathol. 2006;34(12):807-811.

33. Zorn KC, Orvieto MA, Mikhail AA, et al. Solitary ureteral metastases of renal cell carcinoma. Urology. 2006;68(2):428.e425-427.

34. Bosco M, Carucci P, Pacchioni D, et al. Endoscopic ultrasound-guided fine needle aspiration diagnosis of extramedullary hematopoiesis in mediastinum. Endoscopy. 2009;41(suppl 2):E6-E7.

35. Wright PK, Thiryayi SA, Rana DN. Fine needle aspiration cytology diagnosis of extramedullary haematopoiesis presenting as a pre-sacral mass: a pitfall avoided. Cytopathology. 2012;23(2):133-134.

36. Williamson SR, Mast KJ, Cheng L, Idrees MT. Clear cell renal cell carcinoma with intratumoral and nodal extramedullary megakaryopoiesis: a potential diagnostic pitfall. Hum Pathol. 2014;45(6):1306-1309.

37. Makoni SN, Laber DA. Clinical spectrum of myelophthisis in cancer patients. Am J Hematol. 2004;76(1):92-93.

38. Koch CA, Li C-Y, Mesa RA, Tefferi A. Nonhepatosplenic extramedullary hematopoiesis: associated diseases, pathology, clinical course, and treatment. Mayo Clin Proc. 2003;78(10):1223-1233.

39. Sauer B, Buy X, Gangi A, Roy C. Exceptional localization of extramedullary hematopoiesis: presacral and periureteral masses. Acta Radiol. 2007;48(2):246-248.

40. Redmond J 3rd, Kantor RS, Auerbach HE, Spiritos MD, Moore JT. Extramedullary hematopoiesis during therapy with granulocyte colonystimulating factor. Arch Pathol Lab Med. 1994;118(10):1014-1015.

41. Comereski CR, Peden WM, Davidson TJ, Warner GL, Hirth RS, Frantz JD. BR96-doxorubicin conjugate (BMS-182248) versus doxorubicin: a comparative toxicity assessment in rats. Toxicol Pathol. 1994;22(5):473-488.

42. Sohawon D, Lau KK, Lau T, Bowden DK. Extra-medullary haematopoiesis: a pictorial review of its typical and atypical locations. $J$ Med Imaging Radiat Oncol. 2012;56(5):538-544.

43. Zhou PP, Clark E, Kapadia MR. A systematic review of presacral extramedullary haematopoiesis: a diagnosis to be considered for presacral masses. Colorectal Dis. 2016;18(11):1033-1040.

44. Georgiades CS, Neyman EG, Francis IR, Sneider MB, Fishman EK. Typical and atypical presentations of extramedullary hemopoiesis. AJR Am J Roentgenol. 2002;179(5):1239-1243.

45. Ginzel AW, Kransdorf MJ, Peterson JJ, Garner HW, Murphey MD. Mass-like extramedullary hematopoiesis: imaging features. Skeletal Radiol. 2012;41(8):911-916. 


\section{Supplementary material}

Table SI Summary of the basic characteristics of patients

\begin{tabular}{|c|c|c|c|c|c|c|c|}
\hline Citation & Sex & Age & $\begin{array}{l}\text { Malignant } \\
\text { solid tumor }\end{array}$ & Location of EMH & Hematopathy & $\begin{array}{l}\text { Therapy } \\
\text { of EMH }\end{array}$ & Outcome \\
\hline Meykler et al' & $M$ & 64 & Renal cancer & Pleura & $\mathrm{N}$ & None & NA \\
\hline Bowen et $\mathrm{al}^{2}$ & $\mathrm{~F}$ & 72 & Breast cancer & lymph nodes & $Y$ & Surgery & DOM \\
\hline Pantanow et $\mathrm{al}^{3}$ & $M$ & 47 & Kaposi's sarcoma & Pleura & $Y$ & None & SD \\
\hline Takhar et al ${ }^{4}$ & $\mathrm{~F}$ & 53 & Breast cancer & lymph nodes & $\mathrm{N}$ & Surgery & SD \\
\hline Ardakani et $\mathrm{al}^{5}$ & $\mathrm{~F}$ & 44 & EAS & Peritoneum & $\mathrm{N}$ & Surgery & SD \\
\hline Ardakani et $\mathrm{al}^{5}$ & $\mathrm{~F}$ & 30 & EAS & Peritoneum & $\mathrm{N}$ & Surgery & SD \\
\hline Ardakani et $\mathrm{al}^{5}$ & $\mathrm{~F}$ & 56 & OLMS & Peritoneum & $\mathrm{N}$ & Surgery & SD \\
\hline Ardakani et $\mathrm{a}^{5}$ & $\mathrm{~F}$ & 37 & OEC & Peritoneum & $\mathrm{N}$ & Surgery & SD \\
\hline Wang et $\mathrm{al}^{6}$ & $\mathrm{~F}$ & 43 & Breast cancer & Breast & $\mathrm{N}$ & Surgery & NA \\
\hline Wang et $\mathrm{al}^{6}$ & $\mathrm{~F}$ & 38 & Breast cancer & Breast & $\mathrm{N}$ & Surgery & NA \\
\hline Tokumitsu et $\mathrm{al}^{7}$ & $M$ & 52 & Lung cancer & Paraspinal region & $Y$ & Blood transfusion & DOM \\
\hline Yablonski-Peretz et al $^{8}$ & $\mathrm{~F}$ & 43 & Breast cancer & Liver & $Y$ & Blood transfusion & DOM \\
\hline Lemos et $\mathrm{al}^{9}$ & $\mathrm{~F}$ & 50 & Adrenal cancer & Liver & $Y$ & None & NA \\
\hline Prieto-Granada et a $\left.\right|^{10}$ & $\mathrm{~F}$ & 41 & Breast cancer & lymph nodes & $\mathrm{N}$ & Surgery & NA \\
\hline Prieto-Granada et a $\left.\right|^{10}$ & $\mathrm{~F}$ & NA & Breast cancer & lymph nodes & $\mathrm{N}$ & Surgery & NA \\
\hline Prieto-Granada et al ${ }^{10}$ & $\mathrm{~F}$ & 47 & Breast cancer & lymph nodes & $\mathrm{N}$ & Surgery & NA \\
\hline Crider et al" & $M$ & 59 & Lung cancer & Pancreas & $\mathrm{N}$ & $\mathrm{HU}$ & DOM \\
\hline Tamiolakis et al ${ }^{12}$ & $M$ & 62 & Colon cancer & Liver & $Y$ & None & NA \\
\hline Du et $\mathrm{a}^{13}$ & $M$ & 57 & Prostate cancer & Spleen & $\mathrm{N}$ & None & NA \\
\hline Hsu et $\mathrm{al}^{14}$ & $\mathrm{~F}$ & 64 & Lung cancer & Paraspinal region & $\mathrm{N}$ & None & NA \\
\hline Millar et a $\left.\right|^{15}$ & $\mathrm{~F}$ & 36 & Breast cancer & lymph nodes & $\mathrm{N}$ & None & NA \\
\hline Yang et $\mathrm{al}^{16}$ & $\mathrm{~F}$ & 73 & Breast cancer & Mesenterium & $Y$ & None & NA \\
\hline Talmon et $\mathrm{al}^{17}$ & $\mathrm{~F}$ & 49 & Renal cancer & Kidney & $\mathrm{N}$ & Surgery & NA \\
\hline Celik et al ${ }^{18}$ & $\mathrm{~F}$ & 69 & Renal cancer & Kidney & $\mathrm{N}$ & Surgery & NA \\
\hline Orphanidou-Vlachou et al ${ }^{19}$ & $\mathrm{~F}$ & 55 & Renal cancer & Kidney & $\mathrm{N}$ & Surgery & NA \\
\hline Tamm et $\mathrm{a}^{20}$ & $M$ & 53 & $\mathrm{CBCC}$ & Liver & Y & Surgery & NA \\
\hline Arkadopoulos et $\mathrm{a}^{21}$ & $\mathrm{~F}$ & 75 & Breast cancer & Adrenal gland & $\mathrm{N}$ & Surgery & NA \\
\hline Groisman et $\mathrm{a}^{22}$ & $\mathrm{~F}$ & 49 & Breast cancer & Spleen & $\mathrm{N}$ & Surgery & SD \\
\hline Dekmezian et $\mathrm{a}^{23}$ & $\mathrm{~F}$ & I & Liver cancer & Liver & $\mathrm{N}$ & Surgery & DOM \\
\hline Dekmezian et $\mathrm{a}^{23}$ & $\mathrm{~F}$ & 3 & Liver cancer & Liver & $\mathrm{N}$ & Surgery & NA \\
\hline Paydas et $\mathrm{al}^{24}$ & $M$ & 52 & Lung cancer & Paraspinal region & $\mathrm{Y}$ & None & NA \\
\hline Chou et $\mathrm{a}^{25}$ & $\mathrm{~F}$ & 50 & Colon cancer & Kidney & $\mathrm{N}$ & Surgery & NA \\
\hline Lewis et $\mathrm{a}^{26}$ & $M$ & 71 & Renal cancer & Kidney & $\mathrm{N}$ & Surgery & SD \\
\hline Varras et $\mathrm{a}^{27}$ & $\mathrm{~F}$ & 40 & Breast cancer & Endometrium & $\mathrm{N}$ & Surgery & NA \\
\hline Lara et $\mathrm{a}^{28}$ & NA & NA & Lung cancer & Bronchia & $Y$ & None & NA \\
\hline Policarpio-Nicolas et al ${ }^{29}$ & $M$ & 68 & Lung cancer & Spleen & $\mathrm{N}$ & None & NA \\
\hline Zorn et al ${ }^{30}$ & M & 62 & Renal cancer & Ureter & $\mathrm{N}$ & Surgery & NA \\
\hline Bosco et $\mathrm{al}^{31}$ & $\mathrm{~F}$ & 84 & Bladder cancer & Paraspinal region & $\mathrm{N}$ & None & SD \\
\hline Wright et a ${ }^{32}$ & $\mathrm{~F}$ & 66 & EC & Presacral region & Y & None & NA \\
\hline Vassiliou et $\mathrm{a}^{33}$ & $\mathrm{~F}$ & 65 & Colon cancer & Presacral region & $\mathrm{N}$ & None & SD \\
\hline Williamson et $\mathrm{a}^{34}$ & M & 81 & Renal cancer & lymph nodes and kidney & Y & Surgery & NA \\
\hline Makoni et al ${ }^{35}$ & $M$ & 36 & melanoma & Liver, spine and lymph nodes & $\mathrm{N}$ & None & DOM \\
\hline
\end{tabular}

Abbreviations: $C B C C$, cutaneous basal cell carcinomas; DOM, died of malignancy; EAS, endometrial adenosarcoma; EC, endometrial cancer; F, female; M, male; N, no; NA, not available; NPC, nasopharyngeal carcinoma; OEC, ovarian endometrioid adenocarcinoma; OLMS, ovarian leiomyosarcoma; SD, stable disease; Y, yes; EMH, extramedullary hematopoiesis; $\mathrm{HU}$, hydroxyurea.

\section{References}

1. Meykler S, Obstfeld A, Jhala N, Vergara N, Gupta PK. Pleural mass forming extramedullary hematopoiesis masquerading as a malignant neoplasm. Diagn Cytopathol. 2015;43(12):996-999.

2. Bowen JM, Perry AM, Quist E, Akhtari M. Extramedullary hematopoiesis in a sentinel lymph node as an early sign of chronic myelomonocytic leukemia. Case Rep Pathol. 2015;2015:594970.

3. Pantanowitz L, Kuperman M, Goulart RA. Clinical history of HIV infection may be misleading in cytopathology. Cytojournal. 2010;7:7.
4. Takhar AS, Ney A, Patel M, Sharma A. Extramedullary haematopoiesis in axillary lymph nodes following neoadjuvant chemotherapy for locally advanced breast cancer. BMJ Case Rep. 2013;2013:8943.

5. Ardakani NM, Kumarasinghe MP, Spagnolo DV, Stewart CJ. Extramedullary hematopoiesis associated with organizing peritoneal hemorrhage: a report of 5 cases in patients presenting with primary gynecologic disorders. Int J Gynecol Pathol. 2014;33(3):317-322.

6. Wang J, Darvishian F. Extramedullary hematopoiesis in breast after neoadjuvant chemotherapy for breast carcinoma. Ann Clin Lab Sci. 2006;36(4):475-478. 
7. Tokumitsu S, Tokumitsu K, Kohnoe K, Takeya M, Takeuchi T. Extramedullary hematopoiesis presenting as mediastinal tumor. Acta Pathol Jpn. 1980;30(2):315-322.

8. Yablonski-Peretz T, Sulkes A, Polliack A, Weshler Z, Okon E, Catane R. Secondary myelofibrosis with metastatic breast cancer simulating agnogenic myeloid metaplasia: report of a case and review of the literature. Med and Pediatr Oncol. 1985;13(2):92-96.

9. Lemos LB, Baliga M, Benghuzzi HA, Cason Z. Nodular hematopoiesis of the liver diagnosed by fine-needle aspiration cytology. Diagn Cytopathol. 1997;16(1):51-54.

10. Prieto-Granada C, Setia N, Otis CN. Lymph node extramedullary hematopoiesis in breast cancer patients receiving neoadjuvant therapy: a potential diagnostic pitfall. Int J Surg Pathol. 2013;21(3):264-266.

11. Crider S, Kroszer-Hamati A, Krishnan K. Isolated pancreatic extramedullary hematopoiesis. Acta Haematol. 1998;99(1):38-40.

12. Tamiolakis D, Venizelos J, Prassopoulos P, et al. Intrahepatic extramedullary hematopoietic tumor mimicking metastatic carcinoma from a colonic primary. Onkologie. 2004;27(1):65-67.

13. Du E, Overstreet K, Zhou W, et al. Fine needle aspiration of splenic extramedullary hematopoiesis presenting as a solitary mass. A case report. Acta Cytol. 2002;46(6):1138-1142.

14. Hsu FI, Filippa DA, Castro-Malaspina H, Downey RJ. Extramedullary hematopoiesis mimicking metastatic lung carcinoma. Ann Thorac Surg. 1998;66(4):1411-1413.

15. Millar EK, Inder S, Lynch J. Extramedullary haematopoiesis in axillary lymph nodes following neoadjuvant chemotherapy for locally advanced breast cancer--a potential diagnostic pitfall. Histopathology. 2009;54(5):622-623.

16. Yang X, Bhuiya T, Esposito M. Sclerosing extramedullary hematopoietic tumor. Ann Diagn Pathol. 2002;6(3):183-187.

17. Talmon GA. Pure erythropoiesis in clear cell renal cell carcinoma. Int J Surg Pathol. 2010;18(6):544-546.

18. Celik B, Bulut T, Sedele M, Sezer C, Karakus V. Extramedullary hematopoiesis within cystic renal cell carcinoma with oncocytic and chromophobe cell types: A case report. Oncol Lett. 2014;7(3):909-913.

19. Orphanidou-Vlachou E, Tziakouri-Shiakalli C, Georgiades CS. Extramedullary hemopoiesis. Semin Ultrasound CT MR. 2014;35(3):255-262.

20. Tamm EP, Rabushka LS, Fishman EK, Hruban RH, Diehl AM, Klein A. Intrahepatic, extramedullary hematopoiesis mimicking hemangioma on technetium-99m red blood cell SPECT examination. Clin Imaging. 1995;19(2):88-91.

21. Arkadopoulos N, Kyriazi M, Yiallourou AI, et al. A rare coexistence of adrenal cavernous hemangioma with extramedullar hemopoietic tissue: a case report and brief review of the literature. World JSurg Oncol. 2009;7:13.
22. Groisman GM. Lobular Carcinoma of the Breast Metastatic to the Spleen and Accessory Spleen: Report of a Case. Case Rep Pathol. 2016;2016:5160180.

23. Dekmezian R, Sneige N, Popok S, Ordonez NG. Fine-needle aspiration cytology of pediatric patients with primary hepatic tumors: a comparative study of two hepatoblastomas and a liver-cell carcinoma. Diagn Cytopathol. 1988;4(2):162-168.

24. Paydas S, Sargin O, Gonlusen G. PET CT imaging in extramedullary hematopoiesis and lung cancer surprise in a case with thalassemia intermedia. Turk J Haematol. 2011;28(1):60-62.

25. Chou S, Subramanian V, Lau HM, Achan A. Renal Anastomosing Hemangiomas With a Diverse Morphologic Spectrum: Report of Two Cases and Review of Literature. Int J Surg Pathol. 2014;22(4): 369-373.

26. Lewis DJ, Moul JW, Williams SC, Sesterhenn IA, Colon E. Perirenal liposarcoma containing extramedullary hematopoiesis associated with renal cell carcinoma. Urology. 1994;43(1):106-109.

27. Varras M, Stylianido A, Akrivis C, Galanis P, Stefanaki S, Antoniou N. Extramedullary hematopoiesis in the uterine isthmus: a case report and review of the literature. Eur J Gynaecol Oncol. 2002;23(3): 227-230.

28. Lara JF, Rosen PP. Extramedullary hematopoiesis in a bronchial carcinoid tumor. An unusual complication of agnogenic myeloid metaplasia. Arch Pathol Lab Med. 1990;114(12):1283-1285.

29. Policarpio-Nicolas ML, Bregman SG, Ihsan M, Atkins KA. Massforming extramedullary hematopoiesis diagnosed by fine-needle aspiration cytology. Diagn Cytopathol. 2006;34(12):807-811.

30. Zorn KC, Orvieto MA, Mikhail AA, et al. Solitary ureteral metastases of renal cell carcinoma. Urology. 2006;68(2):428 e425-427.

31. Bosco M, Carucci P, Pacchioni D, et al. Endoscopic ultrasound-guided fine needle aspiration diagnosis of extramedullary hematopoiesis in mediastinum. Endoscopy. 2009;41 Suppl 2:E6-7.

32. Wright PK, Thiryayi SA, Rana DN. Fine needle aspiration cytology diagnosis of extramedullary haematopoiesis presenting as a pre-sacral mass: a pitfall avoided. Cytopathology. 2012;23(2):133-134.

33. Vassiliou V, Papamichael D, Lutz S, et al. Presacral Extramedullary Hematopoiesis in a Patient with Rectal Adenocarcinoma: Report of a Case and Literature Review. J Gastrointest Cancer. 2012;43 Suppl 1:S131-135.

34. Williamson SR, Mast KJ, Cheng L, Idrees MT. Clear cell renal cell carcinoma with intratumoral and nodal extramedullary megakaryopoiesis: a potential diagnostic pitfall. Hum Pathol. 2014;45(6):1306-1309.

35. Makoni SN, Laber DA. Clinical spectrum of myelophthisis in cancer patients. Am J Hematol. 2004;76(1):92-93.
Cancer Management and Research

\section{Publish your work in this journal}

Cancer Management and Research is an international, peer-reviewed open access journal focusing on cancer research and the optimal use of preventative and integrated treatment interventions to achieve improved outcomes, enhanced survival and quality of life for the cancer patient. The manuscript management system is completely online and includes

\section{Dovepress}

a very quick and fair peer-review system, which is all easy to use. Visit http://www.dovepress.com/testimonials.php to read real quotes from published authors. 